\title{
PROSOPOGRAFÍA, BIOGRAFÍA PSICOSOCIAL E HISTORIA INTELECTUAL (A PROPÓSITO DE J. V. LASTARRIA)
}

\author{
Prosopography, psychobiography and intellectual history \\ (The case of J. V. Lastarria) \\ Bernardo Subercaseaux*
}

\begin{abstract}
RESUMEN
En relación a la prosopografía, o biografía colectiva, y también a la biografía individual, como métodos para la historia intelectual, se señalan los riesgos y precauciones que estas implican, se releva, sin embargo, la biografía individual que a partir de rasgos psicobiográficos involucra colectivos. Para fundamentar la propuesta se examina el caso de José Victorino Lastarria en relación a dos estudios prosopográficos del siglo XIX chileno. Si bien las pistas con que se reconstituye la autopercepción de Lastarria sobre su lugar en la sociedad, obedecen en gran medida a una percepción subjetiva, sostenemos que la dimensión psicobiográfica debe ser considerada, aun cuando como ocurre en el caso de Lastarria esa visión presente contradicciones con el hecho de que ocupó cargos importantes en una sociedad estamental.
\end{abstract}

Palabras clave: Prosopografía, Lastarria, psicobiográfico, liberalismo, sectores medios.

\begin{abstract}
In relation to prosopography or collective biography, and also regarding individual biography, as methods for intellectual history, the article points out some risks and precautions that should be taken into account. It advocates individual biography considering psychobiographical
\end{abstract}

* Profesor Titular Facultad de Filosofía y Humanidades, Universidad de Chile. Santiago, Chile. Correo electrónico: besuberc@uchile.cl

Artículo recibido el 20 de febrero de 2015. Aceptado el 7 de mayo de 2015. 
features specially those that involve social groups. In support of the proposal it examines the case of Jose Victorino Lastarria in relation to two prosopographic studies of nineteenth century Chile. Reconstructing the tracks of Lastarrias discourse about his place in society, although largely due to a subjective perception, we argue that psychobiographical dimensions must be considered in intellectual history, even if self perception offers -as in Lastarria's casecontradictions with the important positions that he held in a stratified society.

Keywords: Prosopography, Lastarria, psychobiography, liberalism, middle sectors.

\section{BIOGRAFÍA COLECTIVA Y BIOGRAFÍA INDIVIDUAL}

Un Congreso reciente sobre Historia Intelectual celebrado en Buenos Aires (22 de noviembre, 2014) estuvo centrado - desde su convocatoria- en la biografía colectiva como una perspectiva a desarrollar en la historia intelectual de América Latina, evitando así las tradicionales hagiografías sobre grandes figuras, para focalizarse en cambio en la interacción intelectual y en personajes aparentemente insignificantes o fronterizos. Las prosopografías son sin duda una metodología válida y necesaria en la historia intelectual del continente. Pero hay que considerarlas con precaución. Se trata de un ejercicio que necesariamente implica buscar lo común y lo que une, armar andamios y a menudo también poner etiquetas. Al conjugar individualidades y asumir una óptica generalizadora se corre el riesgo de aminorar u omitir las diferencias y prescindir de la sintonía fina. De hecho, en el Congreso de Buenos Aires, esa fue la crítica que se hizo a dos ponencias de tinte prosopográfico, una sobre la Revista Sur y otra sobre los escritores del boom y la Guerra Fría.

También hay riesgos en las biografías individuales, cuando se asume, por ejemplo, un particularismo irrelevante, o se entra en detalles poco pertinentes que pueden ser valiosos para una novela pero no para la historia intelectual.

En la historiografía sobre Chile conocemos solo dos trabajos prosopográficos en que los autores explícitamente declaran que asumen esta metodología, ambos se refieren al siglo XIX. Uno de estos trabajos es un artículo de Bradford Burns (1978) que sostiene la tesis de que la historiografía decimonónica practicada por la élite ilustrada tendría cierta homogeneidad explicable en base a datos de una biografía colectiva de los historiadores más significativos del diecinueve, entre ellos, de Chile M.L. Amunátegui, Barros Arana y Vicuña Mackenna. Rasgos comunes como estudios en el Instituto Nacional, dominio de otras lenguas, vivir en la capital y tener cargos en el Estado explicarían ciertos aspectos ideológicos compartidos que se manifiestan en su quehacer historiográfico ${ }^{1}$.

\footnotetext{
${ }^{1}$ E. Bradford Burns. "Ideology in nineteenth century Latin American historiography", Hispanic
} American Historical Review, 1978. 
El otro trabajo es un libro de Cristián Gazmuri, El 48 chileno (1999). Como se sabe en la década de 1840 se despliega en Chile un movimiento intelectual de filiación ilustrada y liberal, un movimiento que continua y engarza con la generación de la Independencia. "La juventud distinguida -escribe Lastarria- que antes estaba reducida al estrecho círculo [...] de la oligarquía dominante, había recibido -dice- un refuerzo [...] con la nueva generación que se había educado en otros principios y distintas aspiraciones y que sentía estimulada su actividad con el roce de la ilustrada y bulliciosa emigración argentina”. Entre los intelectuales que contribuyen a este clima y que considera Gazmuri (a propósito de la Sociedad de la Igualdad), se cuentan el propio Lastarria, maestro y cronista de su generación, también Francisco Bilbao, Eusebio Lillo, Juan Bello, Antonio García Reyes, Manuel Antonio Matta, además algunos discípulos de los anteriores que se hacen presente a fines de la década del cuarenta y más tarde: entre ellos Manuel Bilbao, Francisco Prado, Federico Errázuriz y Benjamín Vicuña Mackenna. Los datos biográficos de todos ellos -con algunas excepciones- son coincidentes en una prosopografía cuyo itinerario apunta a un liberalismo que tiene su momento más radical entre los ańos 1848 y 1851 . Todos ellos interactúan con los emigrados argentinos de la época de Rosas, fundamentalmente con Sarmiento, Alberdi, Vicente Fidel López y Bartolomé Mitre. En El 48 chileno, Gazmuri, los engloba -me refiero a los chilenos- con el rótulo de una "generación de jóvenes oligarcas", "jóvenes oligarcas" que participaron en los movimientos político revolucionarios de 1850-1851. Señala que años más tarde estos jóvenes llevaron "adelante sus ideales en lo político" (todos o casi todos fueron en la segunda mitad del siglo parlamentarios, ministros o e incluso presidentes o tuvieron cargos importantes a nivel del Estado en su calidad de liberales), sin embargo, agrega, con respecto a "lo social" "adquirieron" "una gran moderación". "Combinación en definitiva -dice Gazmuri- compatible con su condición oligárquica, ya asumida plenamente y con la ideología liberal despojada de los fermentos de revolución social" y del espiritu del 48 que los caracterizó en el pasado.

Aun cuando las ideas liberales ascendentes de los jóvenes que se formaron en las décadas de 1830 y 1840, tienen -como seńala Gazmuri- mucho en común, ellas fueron asumidas no por conciencias-esponjas, sino por individuos concretos de características psicobiográficas muy diferentes. Filológicamente el diccionario de la RAE dice de la prosopografía que es atender o considerar solo el aspecto exterior de una persona, omitiendo por lo tanto su dimensión sicosocial. Aquello que omite el método no deja, sin embargo, de ser significativo. No todos los alumnos de José Joaquín de Mora y de Andrés Bello fueron liberales del mismo modo, cada uno lo fue de una manera distinta. La conciencia, como se sabe, no es un receptáculo inerte, más bien es una función activa, un fluido único e irrepetible que proyecta incesantemente su propio destino en el contexto de rasgos sicobiográficos 
y nichos particulares. Nos interesa, pues, considerar el caso de Lastarria y aclarar algunos rasgos específicos de su conciencia liberal, aquellos que son a nuestro juicio significativos para la historia intelectual.

\section{LIBERALISMO INTRANSIGENTE}

En 1888, Enrique Nercasseaux, a poco de morir el "publicista" Lastarria, decía de él que había sido durante toda su vida "un liberal por convicción y también por temperamento" . Al decir por "convicción" apuntaba sin duda a las ideas, a los principios, a la doctrina política. Y en efecto, desde que en 1836 se inicia como profesor hasta casi la fecha en que muere, la actividad literaria, pedagógica, parlamentaria y diplomática de Lastarria estará orientada por la causa liberal. Tal vez el rasgo distintivo en su caso haya sido la vehemencia con que durante gran parte de su vida difundió esos principios. "Si hubiera de elegirse -escribía Paulino Alfonso en 1917- una persona que representase al liberalismo en Chile, no podría ser sino Lastarria"3.

Pero, ¿qué quería decir Enrique Nercasseaux cuando agregaba que Lastarria era liberal por temperamento? Pensaba sin duda en su idiosincrasia, en su modo específico de ser liberal, en algunos rasgos de personalidad que lo mostraban como liberal aun en actividades que no eran propiamente políticas. En el aula, en el foro, en la tribuna, o en sus cuentos y novelas, puede percibirse una índole enseñadora, un estilo conscientemente predicador, que busca persuadir con la palabra y que recurre a la elocuencia, al tono declamatorio y a la exuberancia verbal, una naturaleza íntima que podría calificarse de docente ${ }^{4}$.

"Me di siempre por liberal -decía al autodefinirse Lastarria, pero nunca por pipiolo ni por representante de partido alguno"s.

Su convicción liberal como instigadora de su acción, carecía para él de parámetros externos; era más bien una causa individual recelosa del proselitismo, una causa moldeada en su propia conciencia, una causa absoluta e ideal. A esta concepción casi religiosa del liberalismo hay que vincular su actitud docente y el modo en que orientó su vida en una especie de sacerdocio liberal. La cara externa de esta concepción fue, en lo político, la intransigencia; la idea de que los principios liberales eran absolutos y cualquiera que fuese la circunstancia no podían

\footnotetext{
${ }^{2}$ Enrique Nercasseaux. "Lastarria", Revista de Artes y Letras. Tomo XIII. Santiago de Chile, 1888.

${ }^{3}$ Paulino Alfonso. "D. J.V. Lastarria”, Revista Chilena. Año 1. Tomo I. Santiago de Chile, 1917.

${ }^{4}$ Alejandro Fuenzalida Grandón. Lastarria y su tiempo. Tomo II. Barcelona, 1911.

${ }^{5}$ José Victorino Lastarria. "Nota de uno de los Diputados de Rancagua al Gobernador de aquel departamento", Revista de Santiago. Tomo III, Santiago de Chile, 1849.
} 
transarse. Lastarria era casi siempre principista. Pensaba que los credos había que mantenerlos incontaminados ${ }^{6}$. En 1880, en sus últimos años, fustigaba todavía las concesiones doctrinarias, la política que él llamaba "de la madre rusa", de esa madre que, sorprendida en las estepas por una manada de lobos, fue arrojando a sus pequeños, uno tras otro, tratando inútilmente de saciar a los lobos, hasta que cayó ella misma devorada:

Ésa -escribió Lastarria- es la política de los sacrificios inútiles... No, no debemos abandonar nunca la lógica y la integridad de las doctrinas. Las reformas a medias, incompletas, truncas, comprometen y des $\neg$ prestigian más de lo que sirven... Yo sé lo que significa eso de que 'es necesario adaptarse a las circunstancias', de que 'es necesario tomar en consideración las costumbres y los hábitos de un pueblo', que 'no se pueden violar las tradiciones', yo sé lo que significa aquello de que 'todavía no estamos preparados para realizar una reforma', y todas esas frases vacías, con que se esconde la cobardía de unos, el egoísmo de otros y la debilidad de todos ${ }^{7}$.

Este liberalismo a ultranza, que solía angostar la realidad al campo de las ideas, pero que portaba también un ángulo contrahegemónico, va acompañado en Lastarria por una actitud algo soberbia y altanera (hay múltiples testimonios al respecto), y también por cierta inflexibilidad (salvo contadas excepciones) respecto de la relación entre los principios y la acción política. A él podría atribuirse aquella frase que dice "sálvese la libertad aunque perezca el mundo".

\section{BIOGRAFÍA PSICOSOCIAL}

La clave de este estilo intelectual parece estar en algunos aspectos psicosociales de su biografía. El padre de José Victorino, después de retirarse del ejército, se estableció en Rancagua, donde un incendio consumió su negocio y sus ahorros. Cuando Lastarria llega a Santiago es un estudiante pobre, cuya familia carece de recursos y no figura en el vecindario decente de la capital. En una sociedad jerarquizada, en la que las familias de la aristocracia terrateniente y mercantil acumulaban poder e influencias, ello representaba una considerable desventaja. El memorialista José Zapiola recuerda que en Santiago algunas escuelas

\footnotetext{
${ }^{6}$ José Victorino Lastarria. Proyectos de ley y discursos parlamentarios. Santiago de Chile, 1857.

${ }^{7}$ Augusto Orrego Luco. "Don Victorino Lastarria, impresiones y recuerdos", Revista Chilena. Año 1, Tomo I, 1. Santiago de Chile, 1917. La voz liberales es de raigambre española, y fue usada según Pedro Grases- en las Cortes de Cádiz (1809-1813) durante las luchas antinapoleónicas, en oposición a serviles, con que se designaba a los acomodaticios. Grases, Pedro. "Liberal voz hispánica", Gremio de discretos. Buenos Aires, 1960.
} 
estaban divididas en dos secciones, no por el grado de rendimiento ni por la clase de estudios, sino por la categoría social a que pertenecía el niño. "Los más distinguidos -dice- ocupaban los dos lados del salón más próximos al maestro, que tenía su asiento en la testera". Otro memorialista señala que entre 1824 y 1834 , franceses e ingleses, con el objetivo de captarse posibilidades comerciales para sus países, concedían en sus buques pases libres a los hijos de las "familias distinguidas de la capital" para seguir estudios en Francia'. A un niño de provincia que llegaba a un mundo estamentado y que carecía de respaldo social, solo le quedaba, para afirmar su individualidad, un camino: el estudio. Del joven rancagüino podría decirse lo que en Martín Rivas se dice del protagonista: "Después del día siguiente (a su llegada de provincia) principió Martín sus tareas con el empeño del joven que vive convencido de que el estudio es la única base de un porvenir feliz, cuando la suerte le ha negado la riqueza"10. Así parece haberlo hecho Lastarria, que fue, recordemos, por sus dotes intelectuales, el alumno de mayor renombre en el Liceo de Chile y, más tarde, elegido por Andrés Bello para asistir a sus lecciones.

Cabe señalar que la educación en esos años era restringida y casi exclusiva para los hijos del vecindario decente, por lo mismo tenía un carácter marcadamente público: en los periódicos se publicaba cada trimestre un informe sobre el progreso de los alumnos, se anunciaba el inicio y el término de las actividades docentes, se publicaban los resultados completos de los exámenes, señalando no solo a los alumnos más destacados sino también a los mediocres y a los malos. Considerando, pues, la situación de Lastarria y el carácter de la sociedad, sobresalir intelectualmente e identificarse con la formación liberal que recibía, representaba para él una necesidad vital, una posibilidad de afirmarse y de trascender su origen.

Un documento de 1839, escrito a los 21 años (y que permaneció inédito hasta 1917) constituye un claro indicio de lo que decimos. Lastarria consigna allí los datos de su formación desde el momento en que ingresa al Liceo de Chile. Da detalles de los cursos que siguió, del día exacto que rindió tal o cual examen y que entró o salió de tal o cual establecimiento. Incluye también los datos de su graduación forense en 1836 y su nombramiento como profesor de Legislación Universal en 1837 y de Derecho de Gentes y Geografía en 1838. Resulta curioso que recuerde con tanta exactitud la fecha de exámenes rendidos hace ya más de una década. Resulta también curioso el propósito del escrito. Hay que descartar el que sea un documento de los que hoy se preparan para conseguir una ocupación, puesto que incluye datos como aquel con que finaliza:

\footnotetext{
${ }^{8}$ José Zapiola. Recuerdos de treinta años, 1810-1842. 8a Edición. Santiago de Chile: Zig-Zag, 1945.

${ }^{9}$ Vicente Pérez Rosales. Recuerdos del pasado. Buenos Aires: W.M. Jackson, 1946.

${ }^{10}$ Alberto Blest Gana. Martín Rivas. Santiago de Chile: Zig-Zag, 1948.
} 
El día 8 de mayo de 1839, me casé con doña Jesús Villarreal, a las 71/2 de la noche ${ }^{11}$.

Parece más bien un recuento íntimo en que revisa lo logrado en 21 años, un documento de reafirmación vital: ¡esto es lo que he llegado a ser y lo que soy! Un documento significativo por la precisión con que rememora sus estudios, y también porque excluye casi todo lo que no esté directa o indirectamente vinculado a su formación ilustrada y liberal. De estos "Papeles inéditos" es también reveladora la lista que compila en noviembre de 1838 "de los libros que poseo" ${ }^{2}$. En Derecho incluye a Vinio, Campomanes, Filangieri (Ciencia de la legislación); Constant (Comentarios a Filangieri); Bentham (Tratado de legislación); Montesquieu (Espiritu de las leyes); Rousseau (Contrato social); Pradt (Concordato de América); Destutt de Tracy (Comentarios sobre las leyes); y también Lamennais (Palabras de un creyente). De literatura tiene poesía y solo algunas Novelas ejemplares de Cervantes y El talismán e Ivanhoe de Walter Scott. En total 263 volúmenes, 118 de derecho y 145 de literatura, historia y geografía. El inventario resulta decidor por los títulos y por el modo en que está concebido: frente a cada obra Lastarria coloca su precio exacto. $\mathrm{Al}$ indicar con tanta precisión su valor está también valorizándose a sí mismo. El libro, no olvidemos, es en el siglo XIX el producto simbólico de mayor prestigio de la cultura ilustrada. Son libros que están integrados a su ser, extensiones de su cuerpo, que le ayudan a enfrentar un medio social que le era adverso.

$\mathrm{Ni}$ en Recuerdos literarios ni en ningún otro escrito se refirió Lastarria a sus padres, a su pasado provinciano o a la ciudad de Rancagua, donde transcurrió parte de su infancia. De su familia, al único personaje que rescata es a su abuelo, Miguel de Lastarria ${ }^{13}$. Un abuelo ilustrado, partidario de reformas liberales en las Cortes Espańolas, defensor en Lima de los derechos de los mulatos y perseguido por la Inquisición por sus ideas antiescolásticas. La vida de Lastaria parece, pues, empezar con su existencia ideológica. Su nacimiento ocurre cuando toma contacto con las ideas liberales, y su padre real cede el paso a la paternidad ideológica de su abuelo. Esta identificación absoluta con los principios indica que Lastarria encuentra en ellos un refugio y una afirmación como individuo. El epíteto de "self made man" que le diera Eugenio María de Hostos, solo se entiende -considerando que Lastarria jamás tuvo fortuna personal- en el contexto de una valorización de la meritocracia que explica esta tenacidad por llevar adelante las ideas liberales, y junto con ellas, a

\footnotetext{
${ }^{11}$ José Victorino Lastarria. "Papeles inéditos de don J.V. Lastarria", Revista Chilena de Historia y Geografía. Año VII. Tomo XXI, 25. Santiago de Chile, 1917.

${ }^{12}$ 'La biblioteca de Lastarria en 1838', "Papeles inéditos de don J. V. Lastarria”, op. cit.

${ }^{13}$ José Victorino Lastarria. "Noticias biográficas de don Miguel de Lastarria”. En Benjamín Vicuña Mackenna. Historia de Santiago. Valparaíso, 1869.
} 
su propia persona. De allí entonces su estilo a veces altanero, su intransigencia y su idiosincrasia -o si se quiere- su firmeza liberal.

Este proceso de reafirmación individual va dejando a través de los años una estela de mofas y burlas, y otra de resentimientos e intransigencias. Era "hombre de pasiones vivas... tan vivas que nunca las ha podido refrenar" decía un comentarista en $1864^{14}$. En Recuerdos literarios, Lastarria evoca a la juventud de fines de la década de 1830 como "una... juventud selecta... y elegante, que figuraba con brillo en la sociedad... dando el tono en los estrados, y mirando por encima del hombro a los pocos jóvenes educados que... se daban por liberales"15. En 1849, momento de acalorada pugna política, El Corsario, diario de los conservadores, llama a Lastarria "Huacho, roto, pícaro" y lamenta que se le hubiera dado educación ${ }^{16}$. Y en 1850 , otro periódico lo pinta en versos satíricos como un pobretón "mal nacido que... por ser algo se desvive", como un predicador de libertades y como un "chuchi fastidioso"17. Lastarria, por su parte, en carta a un amigo íntimo, confiesa "No es patriotismo, ni ambición, ni vanidad" lo que lo mueve, "es sólo odio"18.

Se trata, entonces, de un fenómeno de afirmación individual, pero incrustado en un proceso más amplio de afirmación social. En este sentido, Lastarria representa discursivamente -como lo deja entrever en 1844- los intereses de los todavía incipientes sectores medios ${ }^{19}$. Decimos discursivamente porque su intransigencia liberal lo predispuso a un liberalismo que hizo hincapié en el desarrollo del individuo y en el carácter absoluto de la libertad, más bien que en el aspecto económico o en la democratización efectiva de la sociedad. En el plano discursivo en un ensayo sobre la Colonia cita como ejemplo de las posibilidades de regeneración de una sociedad que todavía conserva rasgos de ese pasado a la clase media, o a lo que él entiende por tal sector:

Bástanos observar esa numerosa clase media, que naciendo en gran parte de aquélla (la última clase de la sociedad), no existía antes de nuestra revolución y que prepara un brillante porvenir a nuestra patria.

En edición de 1868, en Miscelánea histórica y literaria, agrega Lastarria una nota a la cita anterior, donde explica lo que entiende por "clase media" y su confianza en ella. Se trata de una suma social curiosa integrada por algunos antiguos propietarios

\footnotetext{
${ }^{14}$ El Correo Literario, 13, Santiago, 1846.

${ }^{15}$ José Victorino Lastarria. Recuerdos literarios. Santiago de Chile: Zig-Zag, 1967.

${ }^{16}$ José Victorino Lastarria. Diario político 1849-1852. Santiago de Chile: Zig-Zag, 1968.

${ }^{17}$ La República, 5, Santiago de Chile, 9-11, 1850.

${ }^{18}$ Fuenzalida Grandón, op.cit.

${ }^{19}$ José Victorino Lastarria. Investigaciones sobre la influencia social de la conquista y del sistema colonial de los españoles en Chile. Santiago de Chile: Siglo, 1844.
} 
de la Colonia que han perdido sus posiciones, que se fusionan con los propietarios y artesanos ascendentes y que en el futuro -piensa Lastarria- va a llegar a conformar la población industrial acomodada coexistiendo dice "con la población proletaria bajo una misma ley y con el goce de unos mismos derechos". Resulta discutible si se puede hablar de una clase media con esas características a mediados del siglo XIX, sin embargo la identificación simbólica ya es significativa. Así como se identificaba con la clase media y con una concepción meritocrática de la sociedad, Lastarria percibía en los terratenientes al sector que obstaculizaba la meritocracia y el desarrollo social.

Varias veces manifiesta distancia frente a la oligarquía y también frente a los sectores medios o ascendentes que pretendían identificarse con ella, a quienes -según afirma- lapidó para siempre con un neologismo de su invención: "siúticos". Ya maduro, el mismo Lastarria advierte que su susceptibilidad vidriosa está enraizada en motivos biográfico-sociales:

Tuve que luchar -dice- con el ridículo y la difamación, y fui desde el principio burlón para evitar el ridículo y violento para suprimir la difamación. De aquí la susceptibilidad, el excesivo amor propio, el mal genio que me atribuyen y que en general no han sido en mí naturales, sino obra del cálculo y premeditación, tal vez obra del hábito, pero no de un hábito vicioso e inveterado, porque me he vencido siempre que ha sido necesario, y jamás me ha costado vencerme. En la prensa, en los debates parlamentarios, he tenido que ser soberbio, contra lo que me parecía que indicaba desprecio o ridículo, altanero contra el poder que pretendía avasallarme, $\operatorname{dog} \neg$ mático y perentorio contra todo error, implacable contra los espe-culadores y traficantes de la moral y de la política ${ }^{20}$.

La soberbia doctrinaria está vinculada en Lastarria a una autopercibida marginalidad social que va a tener como correlato un tema recurrente en su ficción: el del proscrito, el marginado por razones políticas, ideológicas o sociales. Proscritos son los protagonistas de su relato El mendigo (1843), de El manuscrito del diablo (1849) y de su novela Don Guillermo (1860), personajes maltratados o perseguidos por un mundo en que priman los valores antiliberales. Si bien el tema del proscrito o del vagabundo fue un tema recurrente en el romanticismo literario (el propio Lastarria tradujo en 1840 del francés Le Proscrit de Fredéric Soulié), en Lastarria el uso de esa figura obedece -como hemos argumentado en otra parte- más que a una sensibilidad romántica a una concepción utilitaria de la literatura en pro de una regeneración liberal de la sociedad ${ }^{21}$.

\footnotetext{
${ }^{20}$ Citado por Armando Donoso. Recuerdos de 50 años. Santiago de Chile: Nascimento, 1947.

${ }^{21}$ Bernardo Subercaseaux. "Romanticismo y liberalismo en el primer Lastarria". En José Victorino Lastarria. Obra narrativa. Edición Crítica Hugo Bello. Santiago de Chile: Universidad Alberto Hurtado, (2014): 569-586.
} 
A esta vehemencia singular apuntaba Enrique Nercasseaux cuando decía de Lastarria que era liberal por temperamento. La formación liberal de cuño ilustrada que revelan sus relatos y ensayos y el perfil psicosocial, es decir, por un lado, sus convicciones y, por otro, su temperamento, son por cierto, aspectos que se dan fusionados e interactúan, dándole un tinte contrahegemónico a su pensamiento.

\section{ETIQUETAS Y ANDAMIOS}

Lastarria estuvo lejos de ser un oligarca, y si bien tampoco fue un individuo marginal ni un líder de los sectores medios, no deja de ser significativo la estela que dejó su biografía y su acción política: cuando la Federación de Estudiantes de Chile creó en 1918 una Universidad Popular la bautizó con su nombre: Universidad José Victorino Lastarria, institución vespertina que tenía "el propósito de promover y permitir el avance de las clases proletarias".

No se nos escapa lo que llevó a Gazmuri a utilizar la etiqueta de "jóvenes oligarcas", pues algunos de los que participaron en la Sociedad de la Igualdad efectivamente lo eran. Pero ese rótulo obedece sobre todo a que parte significativa de la historiografía chilena etiqueta el siglo XIX como un período de hegemonía oligárquica, como una sociedad estamental en que el Estado amparó desde la misma Independencia los intereses de la oligarquía, de la hacienda y del mercantilismo, por lo menos hasta el gobierno de Arturo Alessandri, en 1920. La historia, sobre todo la historia política, tiende a crear cajones y andamios para ordenar el pasado, de otro modo correría el riesgo de transformarse en una serie interminable de riachuelos y datos inconexos. La historia intelectual requiere, en cambio, afinar la sintonía, incursionar críticamente en esos cajones o andamios y abrir la posibilidad de nuevas tramas. La visión de Lastarria como un personaje no integrado en una sociedad eminentemente estamental no se condice con quien ocupó cargos de Diputado, Senador, Decano, Jurisconsulto, Embajador y Ministro; sin embargo, aun cuando se trata básicamente de una autopercepción subjetiva, no deja de ser importante tenerla presente al considerar las polémicas y controversias literarias, históricas y políticas en las que él participó (con Bello en la década de 1840, con Sarmiento a propósito del gobierno de Manuel Montt, con Vicuńa Mackenna sobre el gobierno de Portales, con respecto a la fusión en la década de 1870, y con su propio desencanto en Recuerdos Literarios). En esta perspectiva resulta útil prestar atención a las diferencias entre los sujetos, e indagar en los aspectos sicosociales de su biografía, en el modo en que construyen su yo, sobre todo cuando ese yo involucra, aunque sea discursivamente alguna referencia de anclaje social. 


\section{CONCLUSIONES}

Hemos demostrado, me parece, que la prosopografía y el camino deductivo que generaliza y omite los rasgos de sintonía fina, si bien representa una posibilidad en la historia intelectual, debe ser considerado en cuanto método con precaución, pues puede conducir a graves y erróneas simplificaciones, como ocurre en el caso que hemos analizado. Ojo entonces con las prosopografías, y con desechar sin más el valor para la historia intelectual de la dimensión psicosocial de una biografía individual, especialmente cuando ella implica a colectivos o a sectores de la sociedad, aunque solo sea discursiva y simbólicamente.

Cabe señalar también que la focalización en personajes determinados, sobre todo aquellos que han sido construidos como figuras relevantes o heroicas, abre para la historia intelectual la veta de su resignificación, de su uso político a través del tiempo, lo que las convierte en un revulsivo que vincula la biografía individual con una dimensión colectiva y política. Figuras claves en esta perspectiva son personajes como Simón Bolívar que fue un mantuano que anuló su ser mantuano, y cuyo punto de enunciación no fue el caballo del llanero sino el imaginario de la modernidad pasado por el cedazo de un "nosotros" criollo. También es el caso de líderes intelectuales de "abajo" como Doroteo Arango (Pancho Villa) y Emiliano Zapata, personajes que sin duda -a nuestro juicio- deben figurar en una historia intelectual de América Latina, y en cuyo caso resulta compleja una biografía colectiva, vislumbrándose como más productiva una biografía individual con perspectiva sicosocial e histórica, que involucre colectivos. O, también, un estudio de las interpretaciones, resignificaciones y negociaciones que esas figuras han experimentado a lo largo del tiempo.

Finalmente, el método de la prosopografía y de la biografía individual que involucra colectivos, son complementarios y ambos tienen sus riesgos, la prosopografía debe evitar generalizaciones que omitan, desvirtúen o sometan el quehacer intelectual al lecho de Procusto, y las biografías individuales deben cuidarse del particularismo biográfico intrascendente y de todo aquello que no resulte pertinente para la historia intelectual.

\section{REFERENCIAS}

Alfonso, Paulino “D. J.V. Lastarria”, Revista Chilena. Año 1. Tomo I. Santiago de Chile, 1917.

Blest Gana, Alberto. Martín Rivas. Santiago de Chile: Zig-Zag, 1948. 
Bradford Burns, E. "Ideology in nineteenth century Latin American historiography", Hispanic American Historical Review, 1978.

Donoso, Armando. Recuerdos de 50 años. Santiago de Chile: Nascimento, 1947.

Fuenzalida Grandón, Alejandro. Lastarria y su tiempo. Tomo II. Barcelona, 1911.

Lastarria, José Victorino. "Nota de uno de los Diputados de Rancagua al Gobernador de aquel departamento", Revista de Santiago. Tomo III. Santiago de Chile, 1849.

Lastarria, José Victorino. Proyectos de ley y discursos parlamentarios. Santiago de Chile, 1857.

Lastarria, José Victorino. Recuerdos literarios. Santiago de Chile: Zig-Zag, 1967.

Lastarria, José Victorino. Diario politico 1849-1852. Santiago de Chile: Zig-Zag, 1968.

Lastarria, José Victorino. Investigaciones sobre la influencia social de la conquista y del sistema colonial de los españoles en Chile. Santiago de Chile: Siglo, 1844.

Nercasseaux, Enrique. "Lastarria", Revista de Artes y Letras. Tomo XIII. Santiago de Chile, 1888.

Orrego Luco, Augusto. "Don Victorino Lastarria, impresiones y recuerdos", Revista Chilena. Año 1. Tomo I, 1. Santiago de Chile, 1917.

Pérez Rosales, Vicente. Recuerdos del pasado. Buenos Aires: W.M. Jackson, 1946.

Subercaseaux, Bernardo. "Romanticismo y liberalismo en el primer Lastarria". En José Victorino Lastarria. Obra narrativa, Edición Crítica Hugo Bello. Santiago de Chile: Universidad Alberto Hurtado, (2014): 569-586.

Zapiola, José. Recuerdos de treinta años, 1810-1842. 8a edición. Santiago de Chile: Zig-Zag, 1945. 